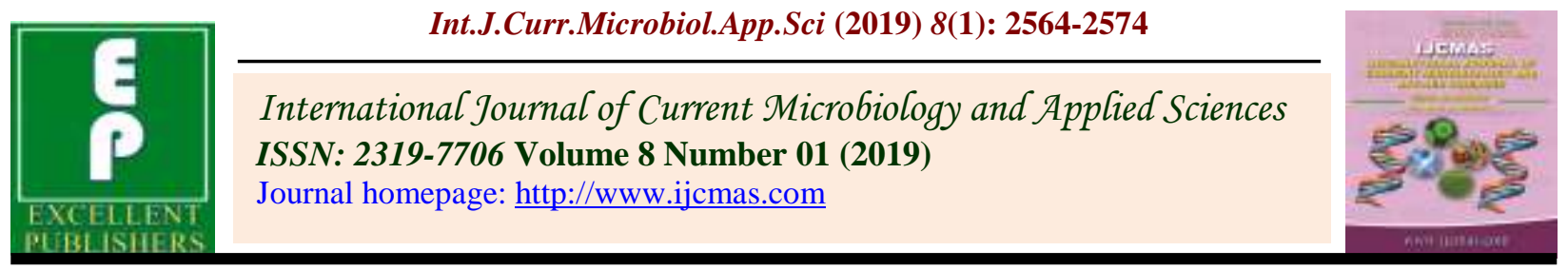

Original Research Article

https://doi.org/10.20546/ijcmas.2019.801.269

\title{
Genetic Diversity Analysis for Drought Tolerance in Indian Mustard (B. juncea L. Czern \& Coss) using Microsatellite Markers
}

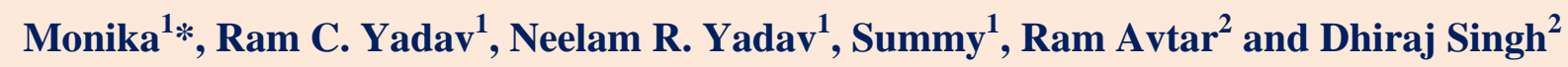 \\ ${ }^{1}$ Department of Molecular Biology, Biotechnology \& Bioinformatics, \\ CCS Haryana Agricultural University, Hisar 125004, India \\ ${ }^{2}$ Department of Genetics \& Plant Breeding, CCS Haryana Agricultural University, \\ Hisar 125004, India \\ *Corresponding author
}

\section{A B S T R A C T}

\begin{tabular}{l} 
K e y w o r d s \\
$\begin{array}{l}\text { SSR primer, } \\
\text { similarity } \\
\text { coefficient, } \\
\text { Polymorphism, } \\
\text { cluster analysis and } \\
\text { Brassica juncea }\end{array}$ \\
\hline Article Info \\
\hline $\begin{array}{l}\text { Accepted: } \\
\text { 18 December } 2018 \\
\text { Available Online: } \\
\text { 10 January } 2019\end{array}$ \\
\hline
\end{tabular}

A total of 200 SSR markers from different Brassica species were used in this study. Out of 200 SSR markers analyzed for polymorphism in two parental Brassica juncea genotypes (RB 50, drought tolerant and Kranti, drought susceptible), 51 were polymorphic. The polymorphic markers were used to screen $F_{2}$ population. A total of 108 alleles were identified in the RB 50 and Kranti and the parental B. juncea genotypes. The PIC (polymorphic information content) values for various primers ranged from 0.340-0.505 with an average of 0.406 . Similarity coefficient data based on the proportion of shared alleles using 51 SSR markers was used to calculate the coefficient values among the 157 $\mathrm{F}_{2}$ plants of RB $50 \times$ Kranti and parental B. juncea genotypes and subjected to UPGMA tree cluster analysis. All the $157 \mathrm{~F}_{2}$ plants clustered in two major groups at the similarity coefficient of 0.53 . Two parental varieties RB 50 and Kranti had low similarity coefficient. Genetic relationship was also assessed by PCA analysis (NTSYS-PC). Two dimensional and three dimensional PCA scaling exhibited that two parental genotypes were quite distinct whereas all $157 \mathrm{~F}_{2}$ plants interspersed between the two parental lines with distribution of most plants towards RB 50.

\section{Introduction}

Brassica juncea, a well-known plant of family Brassicaceae grown widely as an oil crop is one of the major source of edible oil in India. Brassica juncea $(2 \mathrm{n}=36 ; \mathrm{AABB})$ is an amphidiploid derived from chromosome sets of low chromosome number species; Brassica nigra $(2 \mathrm{n}=16 ; \mathrm{BB})$ and Brassica rapa $(2 \mathrm{n}=$ 20; AA) (Srivastava et al., 2001). Indian mustard (Brassica juncea) is a naturally selfpollinated species but recurrent out crossing occurs in this crop with a percentage of 5 to 30 per cent depending upon the environmental conditions and pollinating insect population. The productivity of these crops is greatly subjective of abiotic stresses such as drought, salinity, frost and heat. Water stress causes serious yield losses in Indian mustard (17-94 $\%$ ). Drought reduces yield by affecting plant 
growth which is a genetic character. Mustard genotypes having drought tolerant traits, performed better under water limited conditions in comparison to genotypes without such traits. Abiotic stresses are known to turn on multigene responses resulting in changes in various proteins, primary and secondary metabolite accumulation. Water is the crucial limiting factor for photosynthesis, growth and net ecosystem productivity of plants in arid ecosystems (Luo et al., 2014). Plants respond to drought stress through a series of physiological, cellular and molecular processes culminating in stress tolerance. Drought tolerance is a quantitative trait involving many genes with cumulative effects.

Breeding for drought tolerance is generally considered slow due to the quantitative and temporal variability of available moisture across years, the low genotypic variance in yield under these conditions, and inherent methodological difficulties in evaluating component traits (Ludlow and Muchow, 1990), together with the highly complex genetic basis of this trait (Turner et al., 2001). Due to complex nature of drought tolerance trait and its laborious screening, there is a need to exploit molecular techniques. The long time to develop improved varieties using the conventional plant breeding methods therefore motivated breeders to find tools that help them achieve goals faster. Therefore, traditional plant breeding has not been successful in producing drought tolerant cultivars therefore, QTL identification and MAS for drought tolerance is of prime importance for developing tolerant varieties of Brassica using molecular approaches. Nearly all modern plant breeding relies on molecular markers and they have myriad uses. The advent of various molecular markers has made it possible to assess genetic variability, identify genotypes and perform phylogenetic analysis as well as to devise conservation strategies and perform marker-assisted selection and breeding (Cordoza and Steward, 2004).

Molecular markers have been used to produce genetic maps that represent the genome based on the recombination frequency of the polymorphic markers within a mapping population. Simple sequence repeat $\mathrm{SSR} /$ microsatellite markers are simple tandem repeat of di- to tetra-nucleotide sequence motifs flanked by unique sequences. They are valuable as genetic markers because they are co-dominant, detect high levels of allelic diversity and easily and economically assayed by PCR techniques. SSR markers can distinguish different alleles of a locus that make it more powerful. Therefore, SSR markers have become the markers of choice for a wide spectrum of genetic, population, and evolutionary studies (Agarwal et al., 2008). Several researchers have developed the genetic linkage maps of $B$. juncea using various types of molecular markers such as RFLP, RAPD (Sharma et al., 2002), AFLP (Lionneton et al., 2002; Pradhan et al., 2003; Ramchiary et al., 2007). Identification of molecular markers for drought tolerance is difficult task as it influenced by various factors like days to flowering and maturity, early shoot growth vigor, yield, shoot biomass production, rooting depth, root length density, root to shoot ratio, total transpiration, and transpiration efficiency (Varshney et al., 2011). Therefore, dissection of such complex traits into components and identification of tightly linked markers for such traits can enhance the heritability of such traits and facilitate MAS for introgression of these traits into the different genetic backgrounds. Once molecular markers (i.e. for trait QTLs) linked to specific drought tolerance component traits found, it is possible to move them into adapted cultivars or other agronomic backgrounds through marker-assisted breeding. Moreover, identification of QTLs for the key traits responsible for improved productivity under 
drought could be helpful in accelerating the process of pyramiding of favourable alleles into adapted genotypes for better production.

The present investigation was done to evaluate the genetic diversity in Indian mustard genotypes for drought tolerance. Genetic diversity analysis will help in introgression of drought tolerant genes into other high yielding cultivars to combat from drought stress.

\section{Materials and Methods}

\section{Plant Materials}

The parental lines (RB 50 and Kranti) and 157 $\mathrm{F}_{2}$ progeny lines of Brassica juncea were procured from the oilseed section, Department of Genetics \& Plant Breeding, CCSHAU, Hisar. All the $157 \mathrm{~F}_{2}$ lines were selfed to obtain $\mathrm{F}_{2: 3}$ progeny lines.

\section{Genomic DNA isolation}

Genomic DNA was isolated from young leaves using CTAB method (Saghai-Maroof et al., 1984). The precipitated DNA was washed with $70 \%$ ethanol and dried overnight at room temperature. The dried pellets were dissolved in T.E. buffer (1M Tris, $0.5 \mathrm{M}$ EDTA and $\mathrm{pH}$ 8.0). The DNA quality and concentration were checked by electrophoresis in $0.8 \%$ agarose gel and UV spectrophotometer

\section{PCR amplification}

SSR markers were used to evaluate genetic variability among the Indian mustard genotypes. PCR amplifications were performed using T100TM thermocycler. The total volume of PCR reaction was $20 \mu \mathrm{l}$ per sample, containing $1 \mu \mathrm{l}$ DNA, $2 \mu \mathrm{l}$ of $10 \mathrm{X}$ PCR buffer with $\mathrm{MgCl}_{2}, 0.4 \mu \mathrm{M}$ each forward and reverse primers (Integrated DNA Technology, India),200 $\mu \mathrm{M} \quad \mathrm{dNTP} \quad(\mathrm{G}$ Biosciences) and 0.5U Taq DNA polymerase
(G Biosciences). The PCR tubes were set on the wells of the thermocycler plate. Then, the machine was run accordingly as, initial denaturation at $95^{\circ} \mathrm{C}$ for $3 \mathrm{~min}$; Denaturation at $94^{\circ} \mathrm{C}$ for $1 \mathrm{~min}$; Annealing at $50-60^{\circ} \mathrm{C}$ for 1 min; Extension at $72^{\circ} \mathrm{C}$ for $1 \mathrm{~min}$; completion of cycling program (40 cycles); Final extension at $72^{\circ} \mathrm{C}$ for $7 \mathrm{~min}$ and reaction were held at $4{ }^{\circ} \mathrm{C}$. The amplified products were separated on $6 \%$ polyacrylamide gels containing ethidium bromide. Molecular weight marker of $20 \mathrm{bp}$ was run with the PCR products. DNA bands were observed on UVtrans-illuminator in the dark chamber of the Image Documentation System.

\section{Data analysis}

For molecular diversity analysis, data was scored as 1 and 0 for each of the SSR locus. The presence of band DNA markers run on agarose/ polyacrylamide gel was taken as one and absence of band was read as zero. The 0/1 matrix was used to calculate similarity genetic distance using simqual'sub-program of software NTSYS-PC (Rohlf, 1990). The resultant distance matrix was employed to construct dendrograms by the un-weighted pair-group method with arithmetic average (UPGMA) subprogram of NTSYS-PC (Numerical Taxonomy System for Personal Computer).

\section{Results and Discussion}

Genomic DNA was isolated from the parental and $157 \mathrm{~F}_{2}$ population plants using standard procedures and agrose gel electrophoresis of isolated DNA was done which showed distinct bands (Fig. 1). Subsequently, a DNA fingerprint database of RB 50 and Kranti was prepared using various SSR markers. Polyacrylamide/agarose gels showing allelic polymorphism for selected markers with parents are shown (Fig. 2). The polymorphic markers were used to screen $F_{2}$ population. A 
total of 200 SSR markers from different Brassica species were used in this study. Out of 200 SSR markers analyzed for polymorphism in two parental Brassica juncea genotypes (RB 50 and Kranti), 51 SSR primers (Table 1) were polymorphic. These 51 SSRs were considered reliable due to their codominant nature (Fig. 3).

Similarity coefficient data based on the proportion of shared alleles using 51 SSR markers was used to calculate the coefficient values among the $157 \mathrm{~F}_{2}$ plants of $\mathrm{RB} 50 \times$ Kranti and parental $B$. juncea genotypes and subjected to UPGMA tree cluster analysis. The allelic diversity was used to produce a dendrogram (cluster tree analysis, NTSYSPC), to demonstrate the genetic relationship (Figure 6). All the $157 \mathrm{~F}_{2}$ plants clustered in two major groups at the similarity coefficient of 0.53. Two parental varieties RB 50 and Kranti had low similarity coefficient. Genetic relationship was also assessed by PCA analysis (NTSYS-PC). Two dimensional and three dimensional PCA scaling exhibited that two parental genotypes were quite distinct whereas all $157 \mathrm{~F}_{2}$ plants interspersed between the two parental lines with distribution of most plants towards RB 50 (Figure 4 and 5 respectively).

PIC (polymorphic information content value) for various primers in our study led to polymorphism related information about various primers. In our study, the PIC (polymorphic information content) values for various primers ranged from $0.340-0.505$ with an average of 0.406 . BRMS-027 was found to be the most informative marker depicting the highest PIC value of 0.505 ; source of this marker is Brassica rapa. BRMS019 primer from Brassica rapa was found with lowest PIC value of 0.340 (Table 1). Several researchers have used SSR markers for diversity analysis in Brassica species (Abbas et al., 2009). In our study, the average PIC values were found to be equal to that of reported by Turi et al., (2012) in B. juncea (0.46). Gupta et al., (2014) reported low PIC value 0.281; Sudan et al., (2016) PIC values ranged from $0.12-0.61$ with an average to 0.314 . PIC values (0.38-0.96) observed by Avtar et al., (2016) were found to be higher than that of our study. Lower number of alleles per locus and lower PIC values may be attributed either to the use of less informative SSR markers, or the presence of lesser genetic diversity among the tested genotypes.

Vinu et al., (2013) evaluated the genetic diversity among 44 Indian mustard (Brassica juncea) genotypes including varieties/ purelines from different agro-climatic zones of India and few exotic genotypes (Australia, Poland and China). A and B genome specific SSR markers were used and phenotypic data on 12 yield and yield contributing traits was recorded. Out of the 143 primers tested, 134 reported polymorphism and a total of 355 alleles were amplified.

Molecular markers have been successfully employed for QTL mapping of drought tolerance. It has provided several dozen target QTLs in Brassica and the closely related Arabidopsis (Hall et al., 2005). Many drought or salt-tolerant genes have also been isolated, like BrERF4, BnLAS and AnnBnl fordrought and salinity tolerance in Brassica rapa and Brassica napus respectively, some of which have been confirmed to have great potential for genetic improvement for stress tolerance (Zhang et al., 2014).

In the present study, DNA fingerprint database of $157 \mathrm{RB} 50 \times$ Kranti $\mathrm{F}_{2}$ plants representing the drought and its related traits variation was prepared using 51 polymorphic SSR markers. The NTSYS-pc UPGMA tree cluster analysis and two dimensional PCA scaling exhibited that two parental genotypes were quite distinct and diverse, whereas $157 \quad \mathrm{~F}_{2}$ plants were 
interspersed between the parental B. juncea genotypes. This also indicates that the population is ideal for linkage mapping and QTL identification.

Thakur et al., (2018) used SSR markers to unravel genetic variations in Brassica species. $100 \%$ cross transferability was obtained for $B$. juncea and three subspecies of B. rapa, while lowest cross-transferability was (91.93) was obtained for Eruca Sativa. The average percentage of cross-transferability across all the seven species was $98.15 \%$. Neighbourjoining-based dendrogram divided all the 40 accessions into two main groups composed of B. Carinata/B. napus/B. Oleoracea using SSR primers. Our studies also clustered all the 157 $\mathrm{F}_{2}$ plants in two major groups at the similarity coefficient of 0.53 . Two parental varieties RB 50 and Kranti had low similarity coefficient. Genetic relationship was also assessed by PCA analysis (NTSYS-PC).

Table.1 DNA polymorphism in RB50 and Kranti varieties of Indian mustard (bp) used

\begin{tabular}{|c|c|c|c|c|c|c|}
\hline \multirow[t]{2}{*}{$\begin{array}{l}\text { Sr. } \\
\text { No. }\end{array}$} & \multirow[t]{2}{*}{$\begin{array}{l}\text { SSR Marker } \\
\text { name }\end{array}$} & \multirow[t]{2}{*}{$\begin{array}{l}\text { Marker } \\
\text { source }\end{array}$} & \multirow{2}{*}{$\begin{array}{l}\text { PIC } \\
\text { Value }\end{array}$} & \multirow[t]{2}{*}{$\begin{array}{l}\text { No. of } \\
\text { alleles }\end{array}$} & \multicolumn{2}{|c|}{$\begin{array}{l}\text { Amplified fragment size } \\
\text { (bp) }\end{array}$} \\
\hline & & & & & RB50 & Kranti \\
\hline 1 & Ni4-F11 & B. nigra & 0.47 & 2 & 170 & 160 \\
\hline 2 & BRMS-037 & B. rapa & 0.49 & 2 & 125 & 120 \\
\hline 3 & BRMS-056 & B. rapa & 0.47 & 2 & 220 & 215 \\
\hline 4 & BRMS-048 & B. rapa & 0.46 & 2 & 180 & 185 \\
\hline 5 & BRMS-003 & B. rapa & 0.47 & 2 & 160 & 155 \\
\hline 6 & BRMS-005 & B. rapa & 0.46 & 2 & 150 & 155 \\
\hline 7 & BRMS-006 & B. rapa & 0.39 & 2 & 170 & 165 \\
\hline 8 & BRMS-008 & B. rapa & 0.50 & 2 & 120 & 115 \\
\hline 9 & BRMS-011 & B. rapa & 0.47 & 4 & 205 & 200 \\
\hline 10 & BRMS-015 & B. rapa & 0.50 & 2 & 140 & 145 \\
\hline 11 & BRMS-017 & B. rapa & 0.48 & 2 & 170 & 165 \\
\hline 12 & BRMS-018 & B. rapa & 0.50 & 2 & 140 & 135 \\
\hline 13 & BRMS-020 & B. rapa & 0.48 & 2 & 130 & 125 \\
\hline 14 & BRMS-027 & B. rapa & 0.505 & 2 & 225 & 230 \\
\hline 15 & BRMS-029 & B. rapa & 0.48 & 2 & 240 & 245 \\
\hline 16 & BRMS-031 & B. rapa & 0.44 & 2 & 180 & 185 \\
\hline 17 & BRMS-042 & B. rapa & 0.45 & 2 & 125 & 120 \\
\hline 18 & SSR Na10-B04 & B. rapa & 0.49 & 2 & 260 & 262 \\
\hline 19 & SSR Na12-D03 & B. rapa & 0.40 & 2 & 120 & 115 \\
\hline 20 & BRMS019 & B. rapa & 0.34 & 3 & 120 & 115 \\
\hline
\end{tabular}




\begin{tabular}{|l|c|l|l|l|l|l|}
\hline $\mathbf{2 1}$ & BRMS040 & B. rapa & 0.42 & 2 & 200 & 195 \\
\hline $\mathbf{2 2}$ & BRMS043 & B. rapa & 0.46 & 3 & 300 & 290 \\
\hline $\mathbf{2 3}$ & BRMS051 & B. rapa & 0.48 & 2 & 260 & 250 \\
\hline $\mathbf{2 4}$ & BRMS026 & B. rapa & 0.46 & 2 & 250 & 252 \\
\hline $\mathbf{2 5}$ & Br_Genomic664 & B. rapa & 0.49 & 2 & 190 & 180 \\
\hline $\mathbf{2 6}$ & Br_Genomic935 & B. rapa & 0.50 & 2 & 185 & 190 \\
\hline $\mathbf{2 7}$ & Br_Genomic946 & B. rapa & 0.50 & 2 & 160 & 155 \\
\hline $\mathbf{2 8}$ & GSS_Bn606 & B. rapa & 0.44 & 2 & 140 & 130 \\
\hline $\mathbf{2 9}$ & GSS_Bn622 & B. rapa & 0.49 & 2 & 170 & 180 \\
\hline $\mathbf{3 0}$ & GSS_Bn624 & B. rapa & 0.47 & 2 & 180 & 190 \\
\hline $\mathbf{3 1}$ & GSS_Bn629 & B. rapa & 0.43 & 2 & 190 & 180 \\
\hline $\mathbf{3 2}$ & U_Brapa421 & B. rapa & 0.44 & 2 & 160 & 155 \\
\hline $\mathbf{3 3}$ & U_Brapa244 & B. rapa & 0.47 & 2 & 260 & 250 \\
\hline $\mathbf{3 4}$ & ENA2 & B. rapa & 0.50 & 2 & 240 & 245 \\
\hline $\mathbf{3 5}$ & ENA6 & B. rapa & 0.47 & 2 & 120 & 115 \\
\hline $\mathbf{3 6}$ & ENA14 & B. rapa & 0.47 & 2 & 200 & 210 \\
\hline $\mathbf{3 7}$ & ENA28 & B. rapa & 0.49 & 2 & 300 & 290 \\
\hline $\mathbf{3 8}$ & EJU4 & B. rapa & 0.44 & 2 & 290 & 280 \\
\hline $\mathbf{3 9}$ & BRMS001 & B. rapa & 0.50 & 2 & 120 & 110 \\
\hline $\mathbf{4 0}$ & Br_Genomic697 & B. rapa & 0.49 & 2 & 200 & 195 \\
\hline $\mathbf{4 1}$ & BN_3F027 & B. rapa & 0.50 & 2 & 155 & 160 \\
\hline $\mathbf{4 2}$ & BN_3F132 & B. napus & 0.43 & 2 & 135 & 130 \\
\hline $\mathbf{4 3}$ & BN_3F003 & B. napus & 0.46 & 2 & 155 & 150 \\
\hline $\mathbf{4 4}$ & BN_3F170 & B. napus & 0.41 & 2 & 145 & 140 \\
\hline $\mathbf{4 5}$ & GSS_Bn583 & B. napus & 0.40 & 2 & 150 & 140 \\
\hline $\mathbf{4 6}$ & ENA19 & B. napus & 0.40 & 3 & 240 & 245 \\
\hline $\mathbf{4 7}$ & ENA10 & B. napus & 0.39 & 2 & 380 & 370 \\
\hline $\mathbf{4 8}$ & ENA9 & B. napus & 0.42 & 2 & 480 & 500 \\
\hline $\mathbf{4 9}$ & SSR Na12-H09 & B. napus & 0.41 & 2 & 255 & 250 \\
\hline $\mathbf{5 0}$ & SSR Na14-D09 & B. napus & 0.42 & 2 & 260 & 250 \\
\hline $\mathbf{5 1}$ & SSR Na14-G06 & B. napus & 0.40 & 2 & 120 & 110 \\
\hline & & & & & \\
\hline
\end{tabular}


Fig.1 Agarose gel showing genomic DNA of parents and 1-37 plants of RB50 x Kranti F2 plants L-lamda DNA, P1-RB50, P2-Kranti

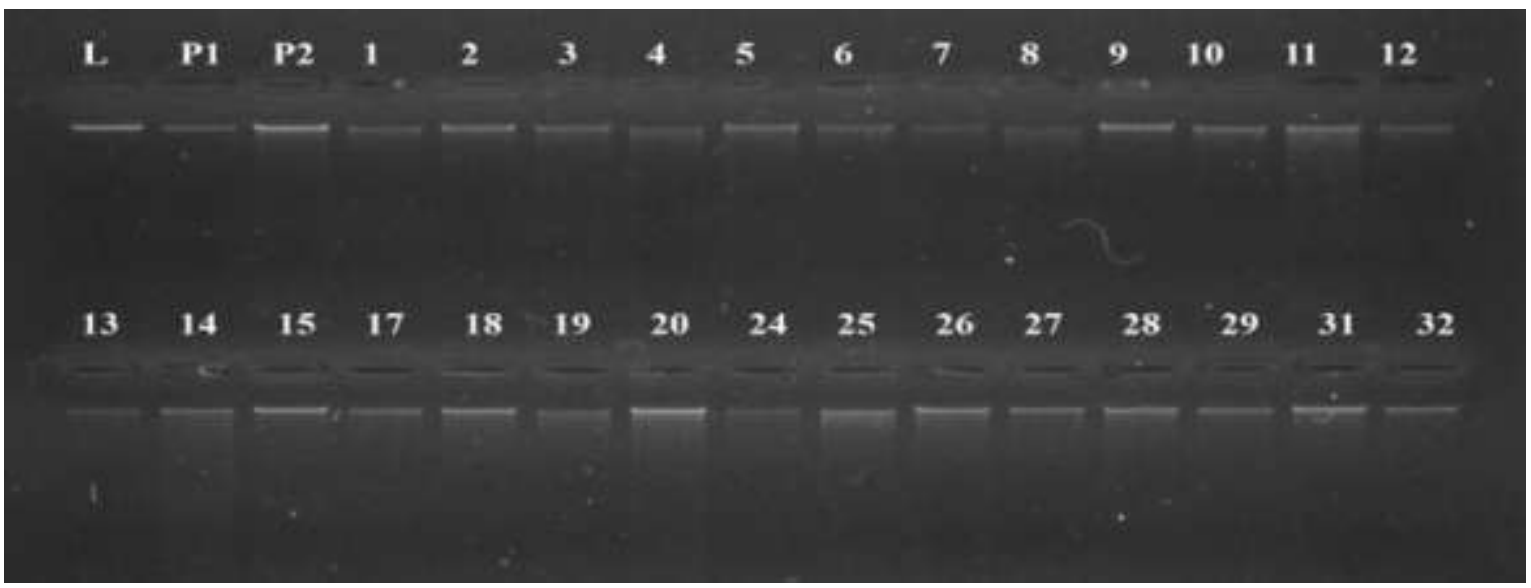

Fig.2 Polyacrylamide gel showing polymorphism among parents P1-Parent 1 (RB50), P2-Parent 2 (Kranti) and Lane L-20 bp ladder

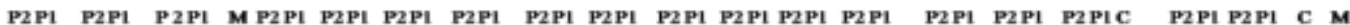

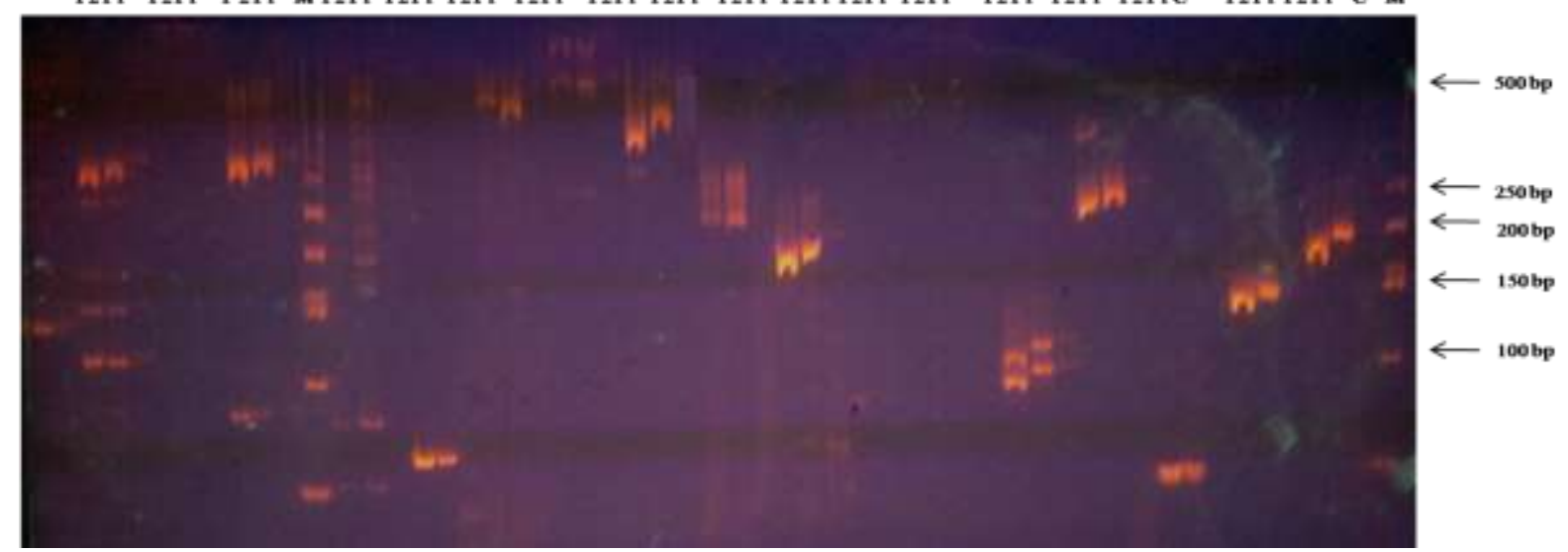

Fig.3 Polyacrylamide gel showing allelic polymorphism among F2 plants at BRMS-056 locus. Lane L-20 bp ladder, 1-42 F2 plants P1-RB50, P2-Kranti

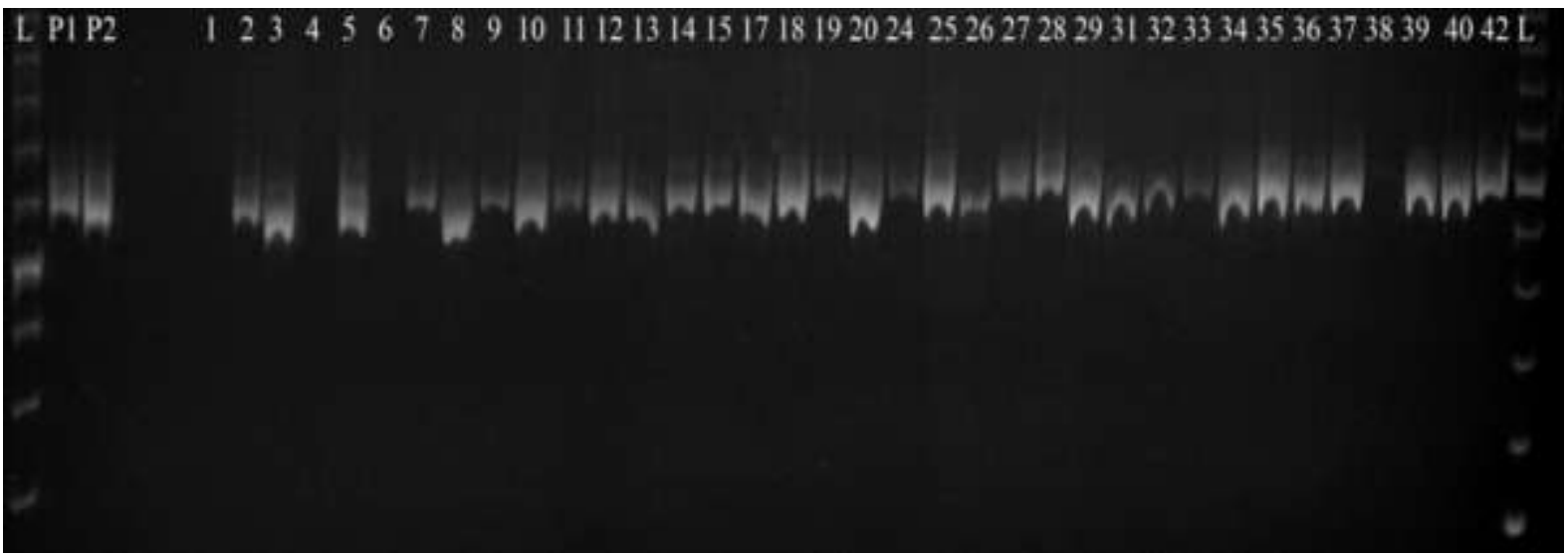


Fig.4 Two dimensional PCA scaling of 157 RB50 x Kranti F2 plants and parental genotypes based on SSR diversity analysis in Indian mustard

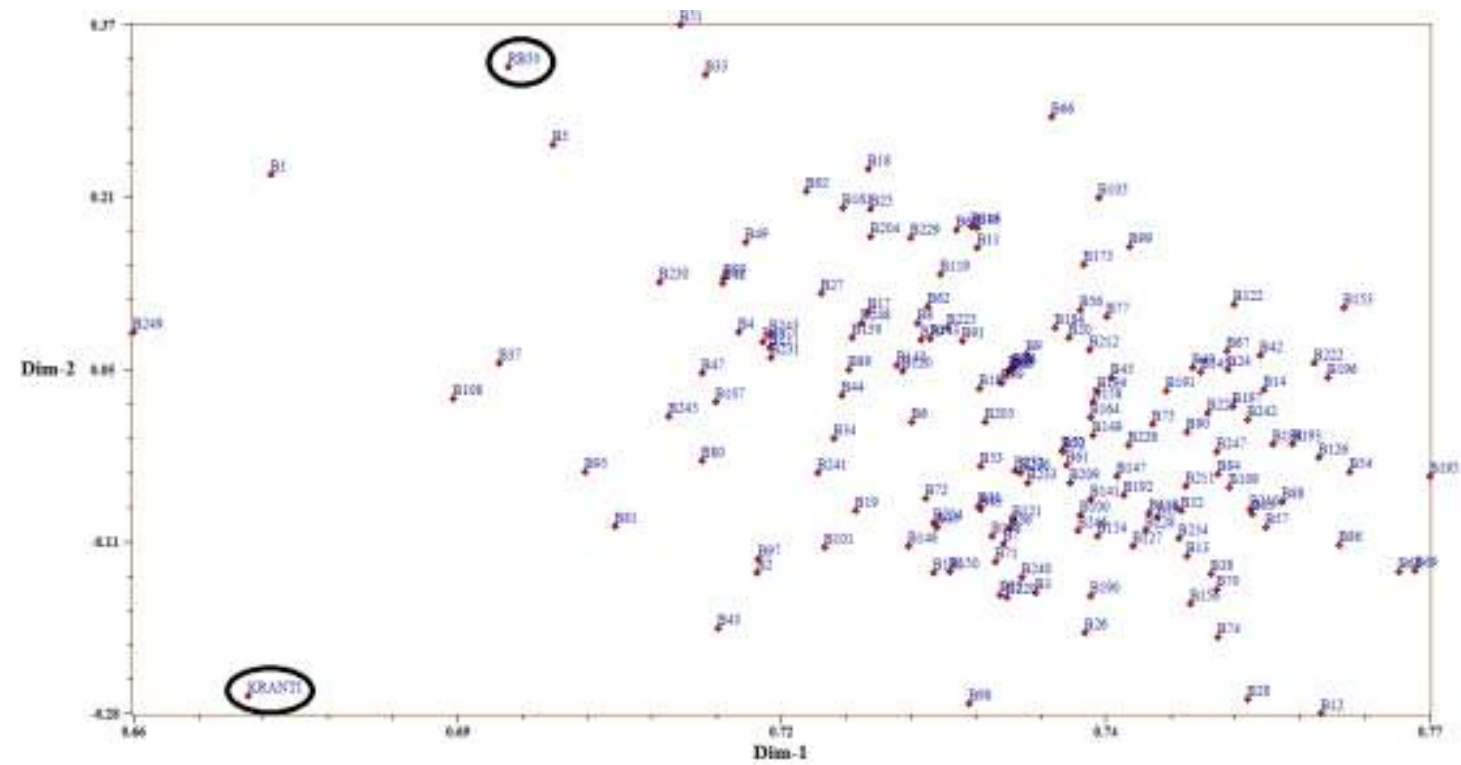

Fig.5 Three dimensional PCA scaling of 157 RB50 x Kranti F2 plants and parental genotypes based on SSR diversity analysis in Indian mustard

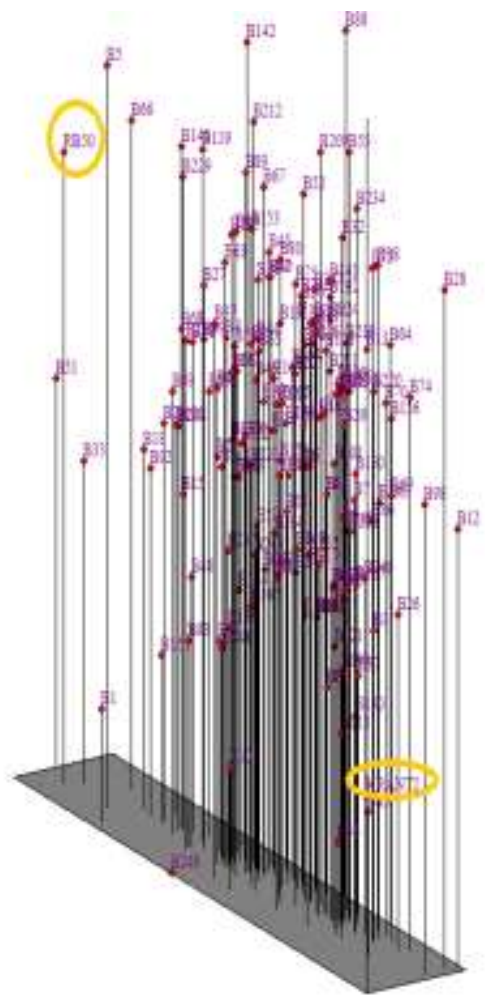


Fig.6 Dendrogram (NTSYS pc, UPGMA) of 157 RB50 x Kranti F2 plants and parental genotypes based on SSR diversity analysis in Indian mustard

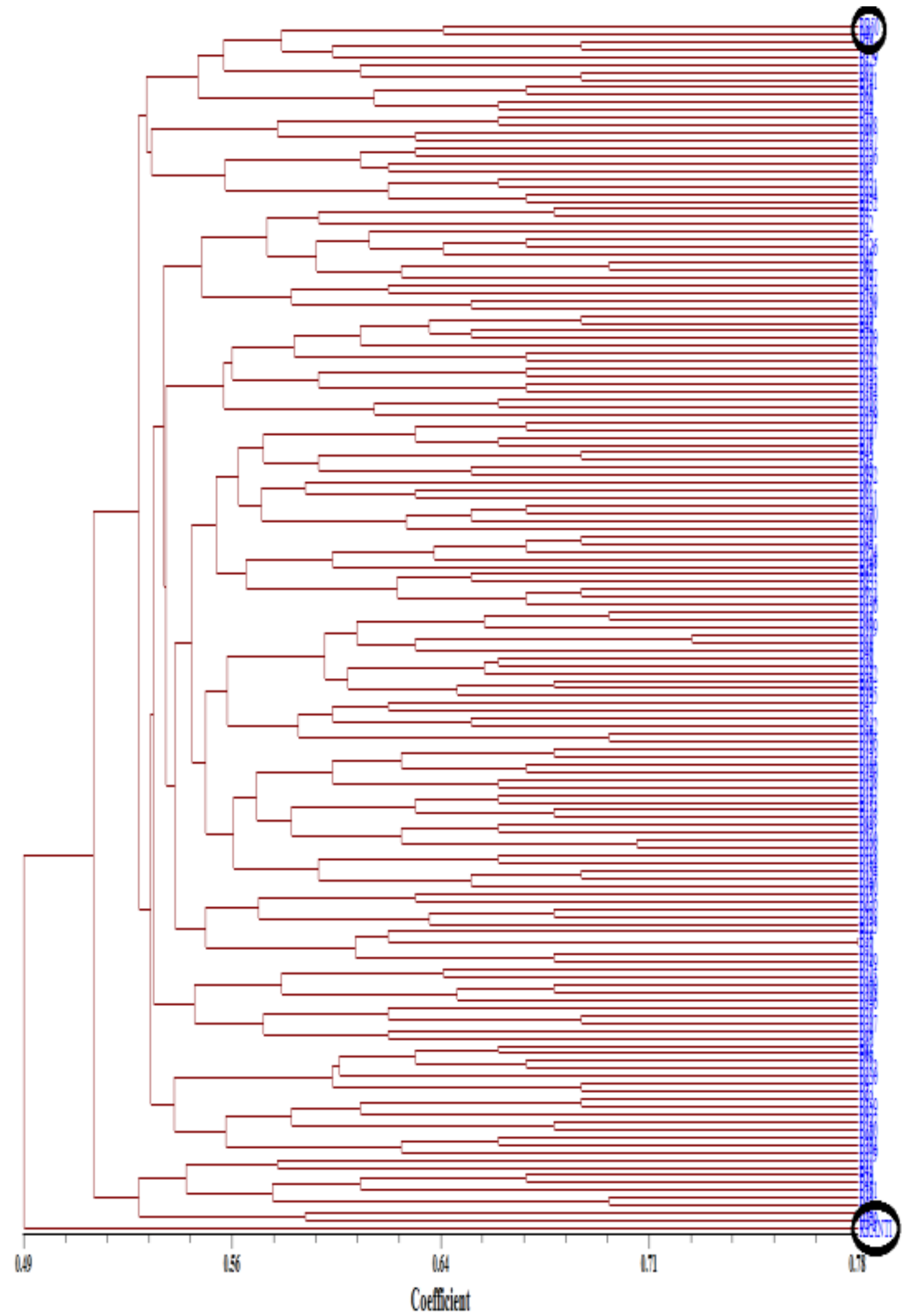


Genetic diversity analysis was performed among $\mathrm{F}_{2}$ plants of the cross $\mathrm{RH} 30 \times \mathrm{CS} 52$ in Indian mustard (Brassica juncea) (CS 52 is salinity tolerant and RH 30 is salinity susceptible) using SSR markers. Out of 358 SSR markers, 42 were found polymorphic and 154 were monomorphic.

A total of 225 alleles, ranging from 2 to 4 were amplified. The PIC (Polymorphic Information Content) value ranged from 0.427-0.730 of Jaccard's similarity coefficients was generated between these $\mathrm{F}_{2}$ populations (Patel et al., 2018). Present study also showed 51 polymorphic primers out of 200 used for polymorphism analysis with total alleles 108 in $\mathrm{F}_{2}$ population of Brassica juncea.

In conclusion, a total of 200 SSR markers from different Brassica species (87 from Brassica rapa, 88 from B. napus, 4 from Brassica nigra, 8 from Brassica oleoracea and 13 from Arabidopsis) were used to screen parental genotypes (RB50 and Kranti) in this study. Out of 200 SSR markers analyzed for polymorphism in two parental B. juncea genotypes (RB 50 and Kranti), 51 (25.5\%) were polymorphic.

Subsequently, a DNA fingerprint database of 150 RB50 x Kranti $F_{2}$ plants using 51 SSR (40 from B. rapa, 10 from $B$. napus and 1 from $B$. nigra) markers to assess the genetic diversity. Diversity analysis by NTSYS-PC software program showed widely diverse nature of both the parental genotypes and all the progeny lines were interspersed between the parents (RB 50 and Kranti) showing wide diversity in population. The population was screened with co-dominant subset of 51 putative polymorphic SSRs. Data for SSR markers was obtained in the form of $\mathrm{ABH}$ scoring which can be then used for map construction and QTL analysis for further cultivar development and analysis in Brassica species.

\section{References}

Abbas, S.J., Farhatullah, Marwat, K.B., Khan, I.A. and Munir, I. 2009. Molecular analysis of genetic diversity in Brassica species. Pak. J. Bot. 41: 167-176.

Agarwal, M., Shrivastava, N. and Padh, H. 2008. Advances in molecular marker techniques and their applications in plant sciences. Plant Cell Rep. 27:617-631.

Avtar, R., Rani, B., Jattan, M., Kumari, M.N. and Rani, A. 2016. Genetic diversity analysis among elite gene pool of Indian mustard using SSR markers and phenotypic variations. The Bioscan. 11(4): 3035-3044.

Cordaza, C. and Steward, C.N. 2004. Invited review: Brassica biotechnology: progress in cellular and molecular biology. In Vitro Cell Dev Biol Plant. 40: 542-551.

Gupta, N., Zargar, S.M., Gupta, M. and Gupta, S.K. 2014. Assessment of genetic variation in Indian mustard (Brassica juncea L.) using PCR based markers. Mol. Plant Breed. 5: 10-17.

Hall, N.M., Griffiths, H., Corlett, J.A., Jones, H.G., Lynn, J. and King, G.J. 2005. Relationships between water use traits and photosynthesis in Brassica oleracea resolved by quantitative genetic analysis. Plant breed. 124(6): 557-564.

Lionneton, E., Ravera, S., Sanchez, L., Aubert, G., Delourme, R. and Ochatt, S. 2002. Development of an AFLP based linkage map and localisation of QTLs for seed fatty acid content in condiment mustard (Brassica juncea). Genom. 45: 1203-1215.

Ludlow, M.M. and Muchow, R.C. 1990. A critical evaluation of traits for improving crop yields in water-limited environments. $A d v$. Agron. 43: 107-153.

Luo, Y., Zhao, X., Qu, H., Zuo, X., Wang, S., Huang, W., Luo, Y. and Chen, M. 2014. Photosynthetic performance and growth traits in Pennisetum centrasiaticum exposed to drought and rewatering under different soil nutrient regimes. Acta Physiol Plant. 36: 381-388.

Patel, R., Yadav, R.C., Jangra, S., Boken, G.D., Singh, B., Yadav, N.R. 2018. Genetic diversity analysis for salinity tolerance in Indian mustard [Brassica juncea (L.)] using 
SSR markers. Int.J.Curr.Microbiol.App.Sci. 7(1): 1776-1785.

Pradhan, A.K., Gupta, V., Mukhopadhyay, A., Arumugam, N., Sodhi, Y.S. and Pental, D. 2003. A high density linkage map in Brassica juncea (Indian mustard) using AFLP and RFLP markers. Theor Appl Genet. 106: 607-614.

Ramchiary, N., Arumugam, N., Gupta, V., Mukhopadhyay, A., Sodhi, Y.S., Pental, D. and Pradhan, A.K. 2007. Mapping of yield influencing QTL in Brassica juncea: implications for breeding of a major oilseed crop of dryland areas. Theor Appl Genet. 115: 807-817.

Rohlf, J. 1990. Numerical taxonomy and multivariate analysis system NTSYS-pc. Department of Ecology and Evolution: New York.

Saghai-Maroof, M., Sliman, A., K.M., Gorgensen, R.A., and Allard, R.W. 1984. Ribosomal DNA spacer- length polymorphism in barley: Mendelian inheritance, chromosomal location and population dynamics. Proc. Natl. Acad. Sci. USA 81:8014-8018.

Sharma, R., Aggarwal, R.A.K., Kumar, R., Mohapatra, T., Sharma, R.P. 2002. Construction of an RAPD linkage map and localization of QTLs for oleic acid level using recombinant inbreds in mustard (Brassica juncea). Genome. 45: 467-472.

Srivastava, A., Gupta, V., Pental, D. and Pradhan, A.K. 2001. AFLP-based genetic diversity assessment amongst agronomically important natural and some newly synthesized lines of Brassica juncea. Theor
Appl Genet. 102:193-199.

Sudan, J., Khajuria, P., Gupta, S.K. and Singh, R. 2016. Analysis of molecular diversity in Indian and Exotic genotypes of Brassica juncea using SSR markers. Indian J. Genet. 76(3): 361-364.

Thakur, A.K., Singh, K.H., Singh, L., Nanjundan, J., Khan, Y.J. and Singh, D. 2018. SSR marker variations in Brassica species provide insight into the origin and evolution of Brassica amphidiploids. Hereditas. 155:6.

Turi, N.A., Farhatullah, Rabbani, M.A. and Shinwari, Z.K. 2012. Genetic diversity in the locally collected Brassica species of Pakistan based on microsatellite markers. Pak. J. Bot. 44: 1029-1035.

Turner, N.C., Wright, G.C. and Siddique K.H.M. 2001. Adaptation of grain legumes (pulses) to water limited environments. Adv. Agron. 71:193-231.

Varshney, R.K., Bansal, K.C., Aggarwal, P.K., Datta, S.K. and Craufurd, P.Q. 2011. Agricultural biotechnology for crop improvement in a variable climate: hope or hype? Trends Plant Sci. 16(7): 363-371.

Vinu, V., Singh, N., Vasudev, S., Yadava, D.K., Kumar, S., Naresh, S., Bhat, S.R. and Prabhu, K.V. 2013. Assessment of genetic diversity in Brassica juncea (Brassicaceae) genotypes using phenotypic differences and SSR markers. Rev. Biol. Trop. 61(4): 19191934.

Zhang, X., Lu, G., Long, W., Zou, X., Li, F. and Nishio, T. 2014. Recent progress in drought and salt tolerance studies in Brassica crops. Breed Sci. 64: 60-73.

\section{How to cite this article:}

Monika, Ram C. Yadav, Neelam R. Yadav, Summy, Ram Avtar and Dhiraj Singh. 2019. Genetic Diversity Analysis for Drought Tolerance in Indian Mustard (B. juncea L. Czern \& Coss) using Microsatellite Markers. Int.J.Curr.Microbiol.App.Sci. 8(01): 2564-2574. doi: https://doi.org/10.20546/ijcmas.2019.801.269 